Article

\title{
Frequency Associations between East Asian Jet Streams and the Temperature over the Barents-Kara Sea Region/Arctic Oscillation in Winter
}

\author{
Yuefeng $\mathrm{Li}^{1, *}$, Yuxiang $\mathrm{Zhu}^{1}$ and Wei Song ${ }^{1,2}$ \\ 1 China Meteorological Administration Training Center, WMO Regional Training Center, \\ 46\# Zhongguancun Nandajie, Beijing 100081, China; zhuyx@cma.gov.cn (Y.Z.); \\ songwei2016@foxmail.com (W.S.) \\ 2 Aviation Meteorological Center, Air Traffic Management Bureau, Beijing 100122, China \\ * Correspondence: liyf@cma.gov.cn
}

Received: 25 August 2020; Accepted: 23 September 2020; Published: 29 September 2020

\begin{abstract}
The frequency associations between jet streams over East Asia and the Arctic key temperature at $2 \mathrm{~m}(\mathrm{AKT} 2 \mathrm{~m})$ in the Barents-Kara Sea region $\left(40^{\circ}-75^{\circ} \mathrm{E}, 66^{\circ}-82^{\circ} \mathrm{N}\right)$ and the Arctic Oscillation in winter are investigated using continuous wavelet transform, cross-wavelet transform, and wavelet coherence. The cross-wavelet transforms between the AKT2m/Arctic Oscillation and the East Asian polar front jet stream (EAPJ) suggest that the EAPJ is closely related to the AKT2m and Arctic Oscillation on an interannual (3-5-year band) timescale, but the variation in the phase angle denotes a complex frequency connection between the EAPJ and Arctic Oscillation. The squared wavelet coherence suggests that weakening of the EAPJ is associated with the rise in AKT2m during the period of abrupt climate change in East Asia. The EAPJ contains more forced components from the Arctic than the East Asian subtropical jet stream. By comparison, the relationship between AKT2m and the EAPJ is closer than that between the Arctic Oscillation and EAPJ, especially during the period of abrupt climate change in East Asia. This suggests that the EAPJ serves as a bridge for Arctic warming to affect the weather and climate over East Asia in winter. By contrast, the Arctic Oscillation does not play an important part, although it also contains information about the Arctic.
\end{abstract}

Keywords: frequency association; Arctic key temperature (AKT2m); Arctic Oscillation; East Asian polar front jet stream (EAPJ); Winter

\section{Introduction}

The Arctic has long been regarded as a key region in various climate change scenarios and is synoptically active [1]. The climate system of the Arctic has undergone substantial changes in recent years, and these changes are widespread in the subcomponents of the Arctic climate [2]. Climate variability can be generated both internally by interactions within or between the individual subcomponents (e.g., the atmosphere, ocean, sea ice, and terrestrial and biological systems) and externally (e.g., volcanic eruptions, variations in solar insolation at the top of the atmosphere, or changes in the atmospheric concentrations of greenhouse gases in response to anthropogenic emissions) [3]. The surface climate of the Northern Hemisphere showed a long-term warming trend in the 20th century, largely caused by anthropogenic forcing but superimposed by natural interdecadal climate variability [3,4]. Polar amplification as a result of meridional heat transport and positive ice-albedo feedback results in more rapid warming at high latitudes than at lower latitudes [5]. There is evidence for a causal connection among the loss of sea ice in the Barents-Kara seas, a stronger Siberian high, and outbreaks of cold air into eastern Asia [6]. Therefore, although covering only a few percent 
of the Earth's surface area, the Arctic may have contributed the largest share of surface warming in the Northern Hemisphere, and perhaps even globally.

The observed decrease in Arctic sea ice is one of the most obvious signs of current global climate change. The extent of Arctic sea ice decreased significantly by $-0.52 \times 10^{6} \mathrm{~km}^{2}$ (5\% per decade) between 1979 and 2007, with a total loss of $1.76 \times 10^{6} \mathrm{~km}^{2}$ [7]. A decrease in Arctic sea ice may have a significant impact on other components of the climate system, including the atmospheric circulation in the Northern Hemisphere. Numerical experiments suggest that the current sea-ice conditions force a remote atmospheric response in late winter that favors cold land-surface temperatures over mid-latitudes, and this has also been observed in recent years [8]. North Pacific sea-ice anomalies force a stationary wave train that propagates far downstream across the Pacific basin along a great circle [9], and can modulate the intensity and position of the Siberian high, Aleutian low, and western Pacific pattern $[8,10-13]$.

Much of the interannual and decadal variability in the atmospheric climate can be described by the evolution of the leading modes of climate variability, such as the Arctic Oscillation and North Atlantic Oscillation. The Arctic Oscillation is the dominant mode of variability in the Northern Hemisphere and has an annular pattern with decreased sea-level pressure (SLP) over the Arctic basin associated with an increased SLP at mid-latitudes, with centers of action over the North Atlantic and North Pacific. There was an abrupt change in the Arctic Oscillation during the 1970s, from negative before 1972 to almost always positive after 1975 [14]. The trends in surface warming and retreat of sea ice in the Arctic between 1980 and 1999 have been largely attributed to the state of the large-scale atmospheric circulation marked by the presence of positive phases of the Arctic Oscillation $[15,16]$. The duration and extent of influence of cold surges in East Asia are different for the positive and negative phases of the Arctic Oscillation, which affect the relevant atmospheric circulations in winter $[17,18]$. The pattern of recent changes in temperature at high latitudes is consistent with, and at least partially attributable to, the corresponding changes in the SLP (gradient wind) field [19]. Dethloff et al. [20] argue that changes in surface processes have the ability to feed back into the global climate system, in part through an atmospheric wave bridge between the Arctic region and lower latitudes.

However, Wu et al. [21] suggested that the Arctic Oscillation does not appear to affect the East Asian winter monsoon (EAWM) on interannual timescales. Gong et al. [17] showed that the Arctic Oscillation accounts for only $13.0 \%$ of the variance in the Siberian high for the period 1958-2000. They suggested that the Arctic Oscillation and Siberian high have relatively independent roles in influencing the EAWM [22]. The winter Arctic Oscillation has a very limited impact on the East Asian climate in other seasons [23]. The relationship between the EAWM and the Arctic Oscillation thus remains an open question [24]. The winter Arctic Oscillation directly influences the surface air temperature, SLP and East Asian trough over the region north of $35^{\circ} \mathrm{N}$ in East Asia, rather than through its impact on the Siberian high [22]. The Arctic Oscillation is not the main cause of temperature fluctuations over East Asia during a weak stratospheric polar vortex event [25]. There are thus different views on how the Arctic Oscillation affects the weather and climate over East Asia.

The EAWM-Arctic Oscillation relationship is not stable and has strengthened during recent decades. The connection between the EAWM and the Arctic Oscillation was statistically non-significant during the period 1950-1970, whereas it was statistically significant during 1983-2012 [24]. The latter significant connection might be attributable to the upstream extension of the East Asian jet stream. The East Asian jet stream signal was relatively more confined to the western North Pacific before the 1970s, whereas it extended westward toward East Asia after the 1980s. This upstream extension has led to the rearrangement of eastward-propagating Rossby waves with a much wider horizontal structure, thereby binding the EAWM and Arctic Oscillation [24].

The most distinct feature of the EAWM is its cold surge activity. As these cold surges move southward with cold, dry continental air, they cause intense drops in temperature over East Asia [24,26]. Early studies indicated that the frequency of the cold surges is related to the variability of the cold Siberian high, warm Aleutian low, East Asian trough in the mid-troposphere, and East Asian jet stream 
in the upper troposphere. In boreal winter, observational evidence shows that the upper-level winds over East Asia are characterized by two jets in the upper troposphere: the East Asian subtropical jet stream (EASJ) and East Asian polar front jet stream (EAPJ) [27]. Temperature variations, particularly Arctic warming in recent years, can affect the meridional temperature gradient [28] and, therefore, also affect the variations in the EAPJ and EASJ through the relation of the thermal winds [29,30]. Arctic warming and changes in the sea-surface temperature may alter the meridional temperature gradients in the troposphere that affect the EASJ and EAPJ, which, in turn, could influence the weather and climate over eastern China [30]. The analysis by Overland and Wang [31] establishes a scientific controversy over the validity of linkages to the inherent intermittency of the dynamics of the jet stream, which provides only an occasional bridge between Arctic thermodynamic forcing and extended mid-latitude weather events.

In some situations, the common behavior in two time series results from one time series driving or influencing the other. In other situations, the common patterns result from some unobserved mechanisms and/or multi-factor interactions influencing both time series. Correlation analysis can determine whether there is a connection between two variables, but it cannot determine in which frequency band the connection is concentrated. Previous studies have mainly focused on the relationship between the Arctic Oscillation and the climate at mid-latitudes. However, the differences in the relationship between the Arctic near-surface temperature/Arctic Oscillation and mid-latitude weather and climate are still unclear.

The current state of research depends on correlation analysis, modeling, case studies, and physical reasoning [6]. In this study, the Arctic key temperature at $2 \mathrm{~m}$ (AKT2m) [32] is used because the atmosphere should respond to the thermal forcing reflected by the anomalous near-surface temperature related to Arctic ice rather than the Arctic ice itself [23]. Previous studies have shown that simulation results can better approximate the actual East Asian climate only when the temperature changes in the Arctic and the associated atmospheric circulation patterns are simulated correctly [33]. The mid-latitude jet tends to shift equatorward (poleward) in models with stronger (weaker) Arctic surface warming [28]. Climate change over East Asia is closely related to Arctic temperature conditions. The winter frequency and temporal variation of the AKT2m, Arctic Oscillation, EAPJ, and EASJ in the upper troposphere $(300 \mathrm{hPa})$, along with their frequency associations and differences, prompted us to explore these issues further because they are meaningful in predictions of changes in the winter climate over East Asia. All of these are correlated with the continuous wavelet transform (CWT), cross-wavelet transform (XWT), and wavelet coherence (WTC) in time-frequency space [34].

Section 2 of this paper describes the datasets and analysis techniques employed in our study. The frequency associations of the AKT2m and Arctic Oscillation are analyzed in Section 3. Section 4 presents the frequency associations between the AKT2m/Arctic Oscillation and jet streams over East Asia, and then our findings and the potential areas for further analysis are summarized and discussed in Section 5.

\section{Data and Methods}

\subsection{Data}

The data used for analysis are from the 67-year (1950-2016) National Centers for Environmental Prediction-National Center for Atmospheric Research (NCEP-NCAR) reanalysis dataset [35] provided by the National Oceanic and Atmospheric Administration/Oceanic and Atmospheric Research/Earth System Research Laboratories Physical Sciences Division (Boulder, CO, USA). The temperature at $2 \mathrm{~m}$ above the Earth's surface on a T62 Gaussian grid $(192 \times 94)$ is used to obtain the AKT2m located over the Barents-Kara Sea region $\left(40^{\circ}-75^{\circ} \mathrm{E}, 66^{\circ}-82^{\circ} \mathrm{N}\right)$, i.e., the AKT2m time series is obtained by the average temperature of all grid points in the region. This is the region with the largest variation in the first mode of the 2-m temperature empirical orthogonal function analysis (EOF) $\left(0^{\circ}-360^{\circ} \mathrm{E}\right.$, 
$\left.55^{\circ}-90^{\circ} \mathrm{N}[32]\right)$, and severe winters across East Asia and the wider Northern Hemisphere are associated with its anomalous warmth [36,37].

There is evidence for a causal connection among the loss of sea ice in the Barents-Kara Sea, a stronger Siberian high, and outbreaks of cold air into eastern Asia [6]. Warming of the Barents-Kara Sea in winter has increased rapidly since 1998 and presents a significant negative correlation with the variation in air temperature over East Asia. Therefore, it is defined as the AKT2m in this study. The $300 \mathrm{hPa}$ zonal and meridional winds $\left(2.5^{\circ} \times 2.5^{\circ}\right.$ global grids, $\left.144 \times 73\right)$ are used to calculate the actual wind speed to investigate the frequency associations with the AKT2m/Arctic Oscillation. The Arctic Oscillation index is obtained from the National Oceanic and Atmospheric Administration Climate Prediction Center website. The Arctic Oscillation index is defined as the time series of the first EOF mode of monthly SLP anomalies poleward of $20^{\circ} \mathrm{N}[38,39]$.

\subsection{Methods}

Many time series are non-stationary, meaning that their frequency changes over time. For these time series, it is important to have a measure of correlation or coherence in the time-frequency plane. Wavelet analysis is carried out by decomposing the time series into a time-frequency space with a multi-time resolution, which allows the determination of the dominant modes of variability and the change in these modes with time [40]. The CWT expands a time series into a time-frequency space where oscillations can be seen in a highly intuitive way. The CWT can be used to analyze time series that contain non-stationary power at many different frequencies, which is a common tool for analyzing localized intermittent oscillations in a time series [34]. XWT and WTC are powerful methods for testing the proposed linkages between two time series.

XWT finds regions in time-frequency space where the time series shows a high common power, and reveals information about the phase estimation [34,41]. WTC is a tool for detecting common time-localized oscillations in non-stationary signals and estimating the coherence or identifying possible relationships between two processes by searching regions in time-frequency space where the two time series co-vary. In other words, WTC may enhance linear and local correlation analyses that help reveal intermittent correlations between two phenomena or signals in time-frequency space, even at intervals where high coherence exists, but only minimal power is shown in the wavelet power spectrum of the two processes $[34,42,43]$. In this way, locally phase-locked behavior is uncovered. The significance level of WTC has to be determined using Monte Carlo methods.

There are differences between the XWT and WTC methods. XWT exposes the common power and relative phase in time-frequency space, whereas WTC can find significant coherence even though the common power is low, as well as show how confidence levels are calculated against red noise backgrounds. The phase relationship of the two time series is shown by the orientation of the arrows in the regions of high coherence-that is, phase arrows pointing right are in-phase, left is antiphase, down is $\mathrm{X}$ leading $\mathrm{Y}$ by $90^{\circ}$, and up is $\mathrm{Y}$ leading $\mathrm{X}$ by $90^{\circ}$. The phase angle can be quantified as a number of years [34].

In this paper, the CWT, XWT and WTC are presented as shaded maps of the wavelet coefficients that represent highs and lows in variance, covariance or coherency, and they are plotted according to their location along the transect and the scale of the variation [44]. The maps are shaded to reveal anomalies representing highs in the wavelet coefficients. The interpretation of the spectra is visual. Significant areas in the spectra are represented by black contours and deep purple shading, which represent those locations and scales at and above the $95 \%$ confidence interval.

Many statistical tests assume that the probability density function is close to normal. Previous experience with CWTs in geophysical time series shows that series that are far from normally distributed produce unreliable and less significant results [34]. Thus, the probability density functions of the AKT2m, Arctic Oscillation, EAPJ, and EASJ need to be confirmed in accordance with or close to a normal distribution. By projecting a time series on a wavelet function, which must be localized in time-frequency space and have a zero mean, decomposition makes it possible to obtain information 
from the local neighborhood [41]. Checking the frequency histograms, probability density estimate, and normal distribution density of these four time series during the winters of 1950-2016 has shown that they are not too far from normally distributed (Figure 1). Thus, the four time series can be used to carry out CWT, XWT and WTC analyses and obtain relatively reliable results.

(a) AKT2m-DJF-1950-2016

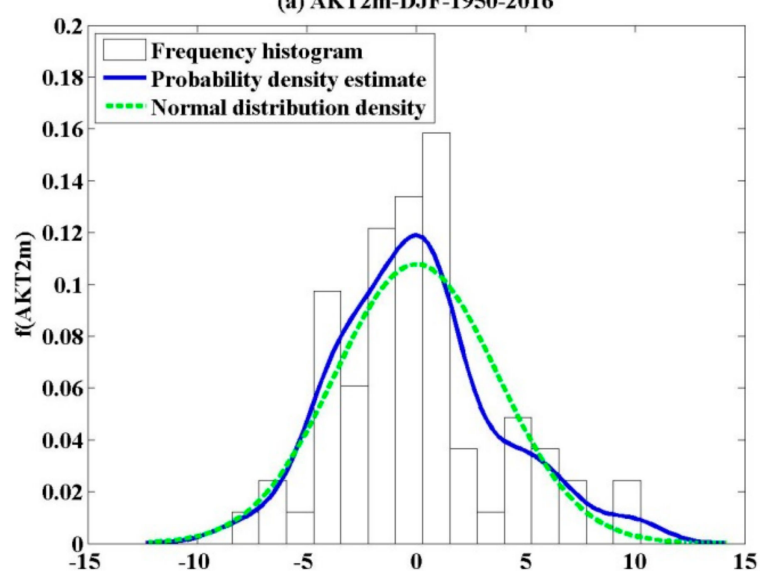

(c) EAPJ-DJF-1950-2016

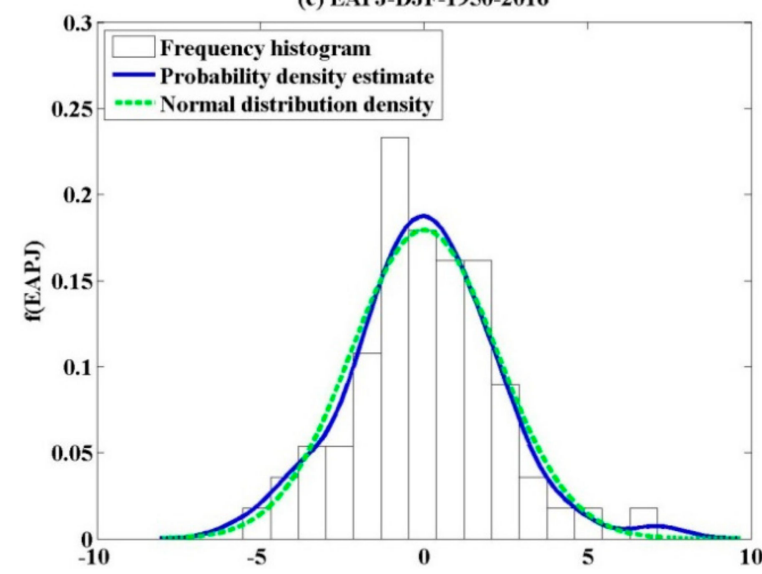

(b) AO-DJF-1950-2016

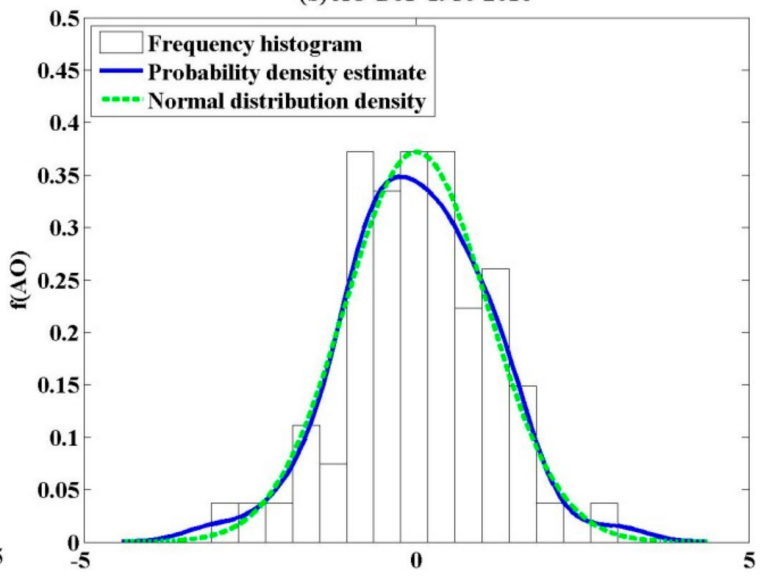

(d) EASJ-DJF-1950-2016

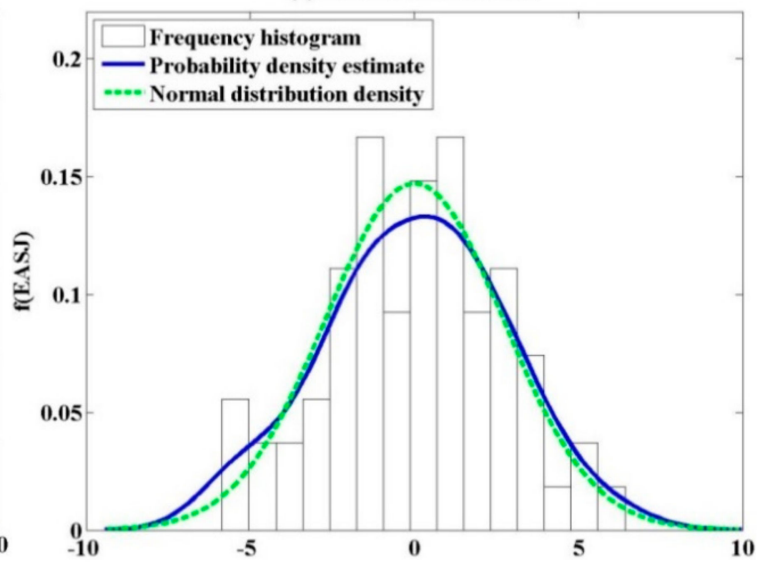

Figure 1. Frequency histogram, probability density estimate (blue solid line), and normal distribution density (dashed green line) for the (a) Arctic key temperature at $2 \mathrm{~m}$ (AKT2m), (b) Arctic Oscillation, (c) East Asian polar front jet stream (EAPJ), and (d) East Asian subtropical jet stream (EASJ) during the winters (December-January-February) of 1950-2016. The $x$-axis coordinates represent the above four variables' anomalies from the 1950-2016 averages.

Winter cold-air activity was examined in terms of the variation in the intensity of the EAPJ $\left(70^{\circ}-110^{\circ} \mathrm{E}, 45^{\circ}-60^{\circ} \mathrm{N}\right)$ and the EASJ $\left(130^{\circ}-160^{\circ} \mathrm{E}, 27.5^{\circ}-37.5^{\circ} \mathrm{N}\right)$ (Figure 2) [45]. For example, when both the EAPJ and EASJ are weak, cold air invades from northern Xinjiang, affecting most of China with a strong intensity and long duration. The intensity indices of the EAPJ and EASJ were determined using the standardized mean regional wind speeds at $300 \mathrm{hPa}$ [45]. 


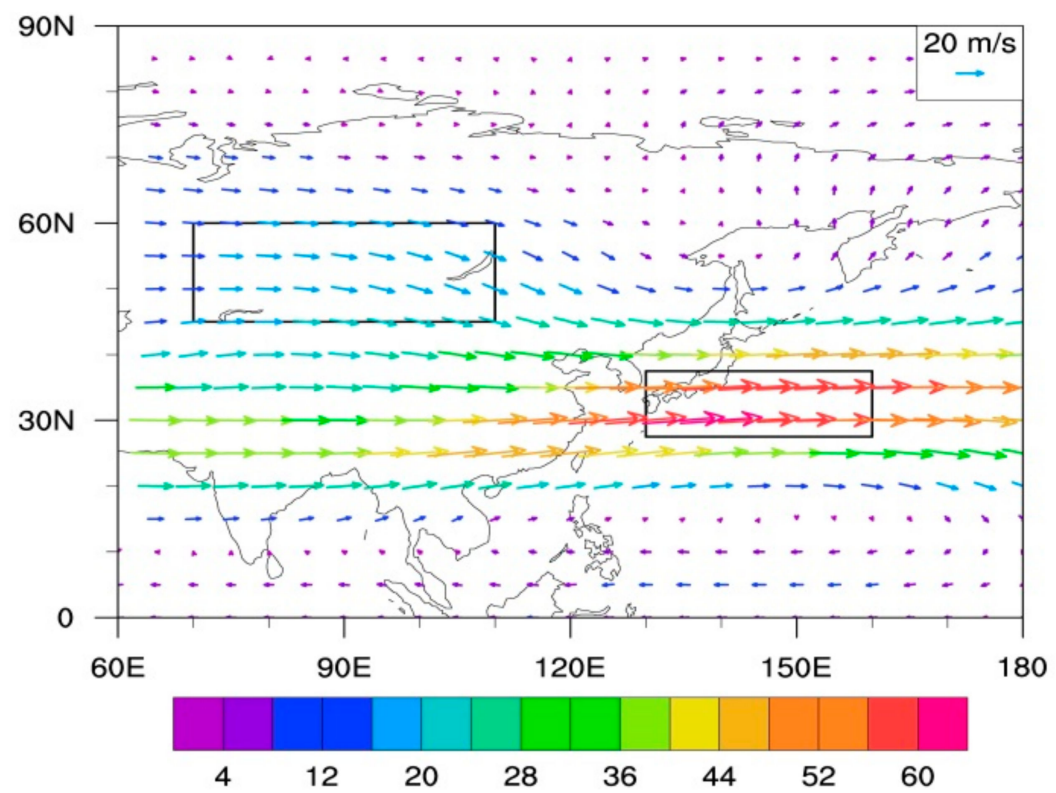

Figure 2. Vector wind composite mean at $300 \mathrm{hPa}$ in the winters of 1981-2010. The upper-left panel $\left(70^{\circ}-110^{\circ} \mathrm{E}, 45^{\circ}-60^{\circ} \mathrm{N}\right)$ and the lower-right panel $\left(130^{\circ}-160^{\circ} \mathrm{E}, 27.5^{\circ}-37.5^{\circ} \mathrm{N}\right)$ are used to measure the strength of the EAPJ and EASJ, respectively.

\section{Frequency Associations between the AKT2m and Arctic Oscillation}

The CWTs of the AKT2m and Arctic Oscillation have their own features in the wavelet power spectrum (Figure 3a,b). The AKT2m series has significant peaks in the 3 to 5 -year period from the mid-1970s to the mid-1980s, and the 4 to 8 -year period from the mid-1990s to the late 2000s (Figure 3a), although these periods do not universally have a significance level $\geq 5 \%$. The high power of the Arctic Oscillation series (Figure $3 \mathrm{~b}$ ) is in the 3 to 5 -year period around the late 2000s, and the 7 to 10-year period from 1970 to 1990 . There is no clear common significant peak or frequency between the AKT2m and Arctic Oscillation.

Figure $3 \mathrm{c}$ shows the XWTs between the AKT2m and Arctic Oscillation. The significant common power is roughly located in the 7 to 10-year band from the mid-1970s and the late 1980s. They also have another common power in the 6- and 3 to 5-year bands, approximately, in the mid- to late 2000s. This indicates that there are some valid phase connections between the AKT2m and Arctic Oscillation, but these are intermittent and limited. Therefore, it can be said that there are only a few accidental connections between the AKT2m and Arctic Oscillation as a result of their non-linear impacts on each other or by other factors. There is a phase angle of about $45^{\circ}$ (between the top and right) between the AKT2m and Arctic Oscillation within the regions of 5\% significance, which confirms our conclusion that the AKT2m and Arctic Oscillation are in-phase, but that the Arctic Oscillation leads the AKT2m. The length of the lead time is related to the position of commonly important periods-for example, $180^{\circ}$ in a 1-year frequency band represents a half-year. Consistent or slowly changing phase angles can be considered as evidence of significant phase relationships [41]. 

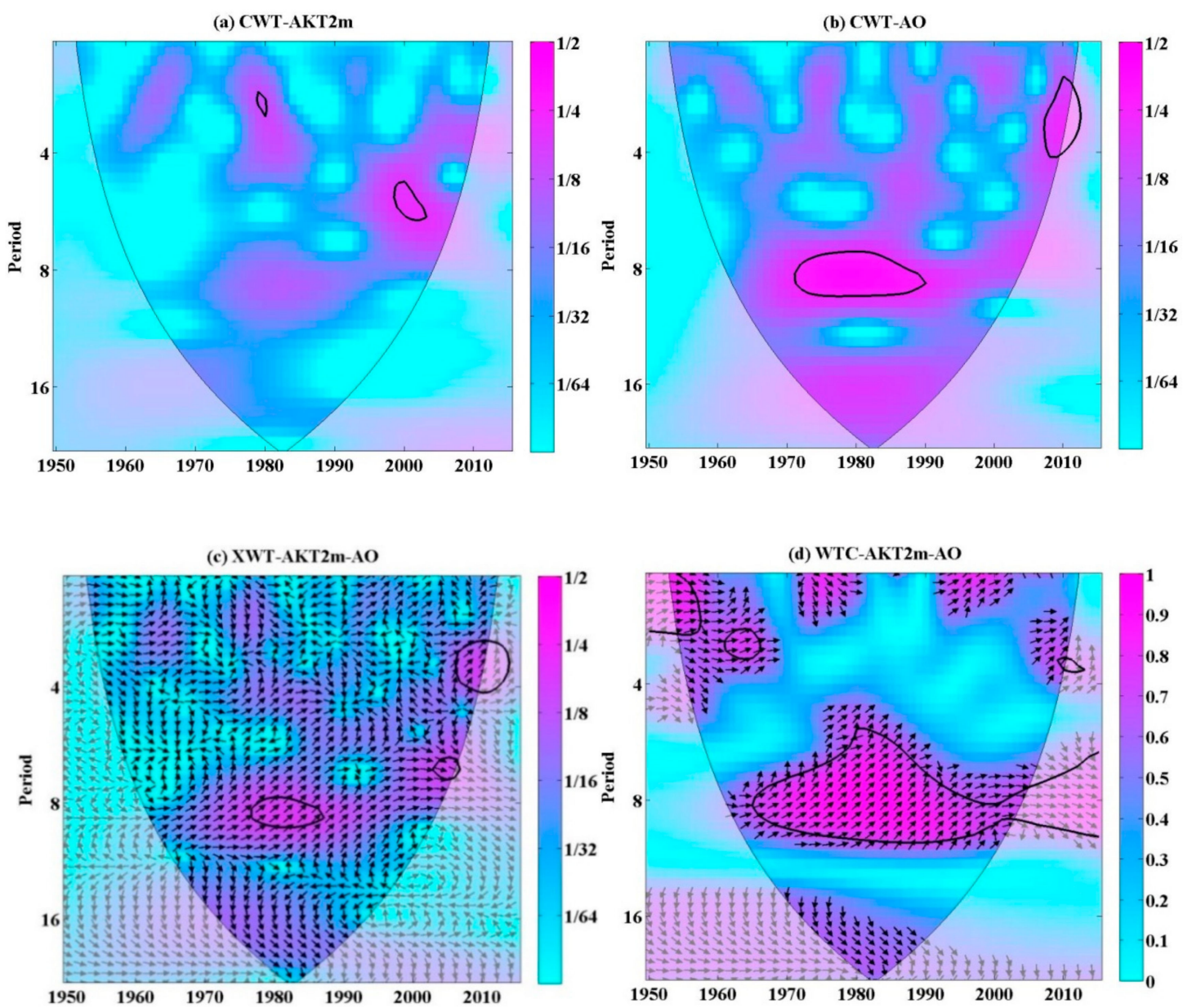

Figure 3. Continuous wavelet power spectra (CWT) for the standardized time series of the (a) AKT2m and (b) Arctic Oscillation; and the (c) cross-wavelet transform (XWT) and (d) squared wavelet coherence (WTC) between the AKT2m and Arctic Oscillation during the winters of 1950-2016. The thick black contour shows the $5 \%$ significance level against red noise and the thin black line indicates the cone of influence where edge effects might distort the picture shown in a lighter shade. The phase relationship of the two time series is shown by the orientation of the arrows in the regions of high common power for XWT or high coherence for WTC - that is, phase arrows pointing right are in-phase, left is antiphase, down is AKT2m leading the Arctic Oscillation by $90^{\circ}$, and up is the Arctic Oscillation leading AKT2m by $90^{\circ}$. The phase angle can be quantified as a number of years.

Figure $3 \mathrm{~d}$ shows the squared WTC of the AKT2m and Arctic Oscillation. Compared with the XWT, a larger section stands out as being significant. The Arctic Oscillation manifests in the AKT2m at periods varying from 5 to 10 years, whereas their connections show stages of time from the mid-1960s to the late 1990s and the period is located within the cone of influence, where edge effects cannot distort the picture. Relative to their XWT, the WTC seems to have stretched forward and backward for 10 years each. Their correlation tends to be in-phase, but the variation in the AKT2m lags behind the variation in the Arctic Oscillation.

\section{Frequency Associations between the AKT2m/Arctic Oscillation and Jets over East Asia}

\subsection{Continuous Wavelet Transform}

Figure 4a,b show the CWTs of the EAPJ and EASJ, respectively. They have a common significant peak in the 3 to 5-year band from the early 1960s to the early 1980s and for EAPJ variability in the midto late 2000s. The EAPJ has a significant peak in the 6 to 8 -year band from the early 1960s to the late 
1970s, whereas the EASJ has a high power in the 16 to 20 -year band from the early 1970 s to the early 1990s. This suggests that the EAPJ and EASJ are not only affected by similar factors in their interannual (3 to 5-year band) variations of the same duration, but are also influenced by different factors in their interannual (6 to 8-year band for the EAPJ from the early 1960s to the late 1970s) and interdecadal (16 to 20-year band for the EASJ from the early 1970s to the early 1990s) variation to different extents during different periods.
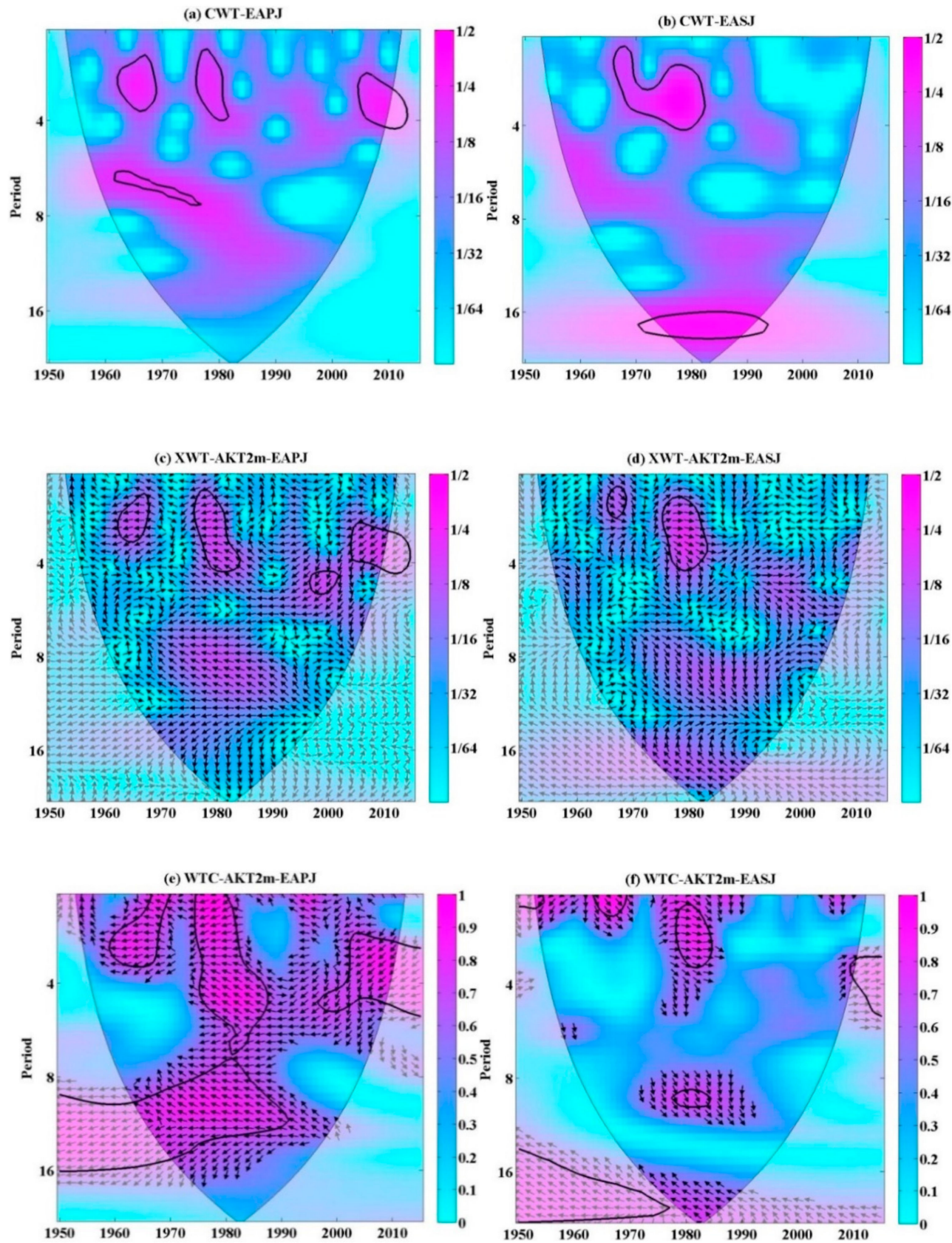

Figure 4. Continuous wavelet power spectra (CWT) for the standardized time series of the (a) EAPJ and (b) EASJ, the cross-wavelet transform (XWT) of the (c) AKT2m and EAPJ and (d) AKT2m and EASJ, and the squared wavelet coherence (WTC) of the (e) AKT2m and EAPJ and (f) AKT2m and EASJ during the winters of 1950-2016. The thick black contour shows the 5\% significance level against red noise, and the thin black line indicates the cone of influence where edge effects might distort the picture shown in a lighter shade. 


\subsection{Cross-Wavelet Transform}

The XWT between the AKT2m and EAPJ shows the highest common power in the 3 to 5 -year band intermittently from the 1960s to the 2010s (Figure 4c), which is similar to the CWT of the EAPJ and the CWT of the AKT2m, which intermittently present a remarkable peak in the 3 to 5 -year band (Figure 2), albeit with most not reaching the 5\% significance level. The XWT phase of the AKT2m and EAPJ tends to be mostly out-of-phase. The XWT of the AKT2m and EASJ show a similar high common power in the 3 to 5 -year band, mostly in-phase (Figure $4 \mathrm{~d}$ ) in the relatively short period from the mid-1970s to the early 1980s. This reflects the difference between the EAPJ and EASJ only from the perspective of Arctic warming.

The XWT of the Arctic Oscillation and EAPJ (Figure 5a) shows a significant common power located in about the 3 to 5-year band during the 1960s, 1970s and 2005-2010, and in the 6 to 10-year band from the early 1970s to the late 1980s at the $>5 \%$ significance level, similar to the XWT of the AKT2m and EAPJ. The XWT shows their significant common power to be antiphase in most of these periods except the 1970s. Therefore, we cannot simply conclude that the EAPJ can definitely mirror the Arctic Oscillation, although there are some phase associations with their significant common power. However, their phase connections are complex, possibly due to the overlap of multiple valid variations, and non-linear impact by some factors. These analyses show that the EAPJ contains some forced components from signals in the 3 to 5- and 6 to 10-year bands of the Arctic Oscillation and AKT $2 \mathrm{~m}$, although the XWT of the AKT2m and EAPJ in the 6 to 10 -year band does not reach the $5 \%$ significance level.
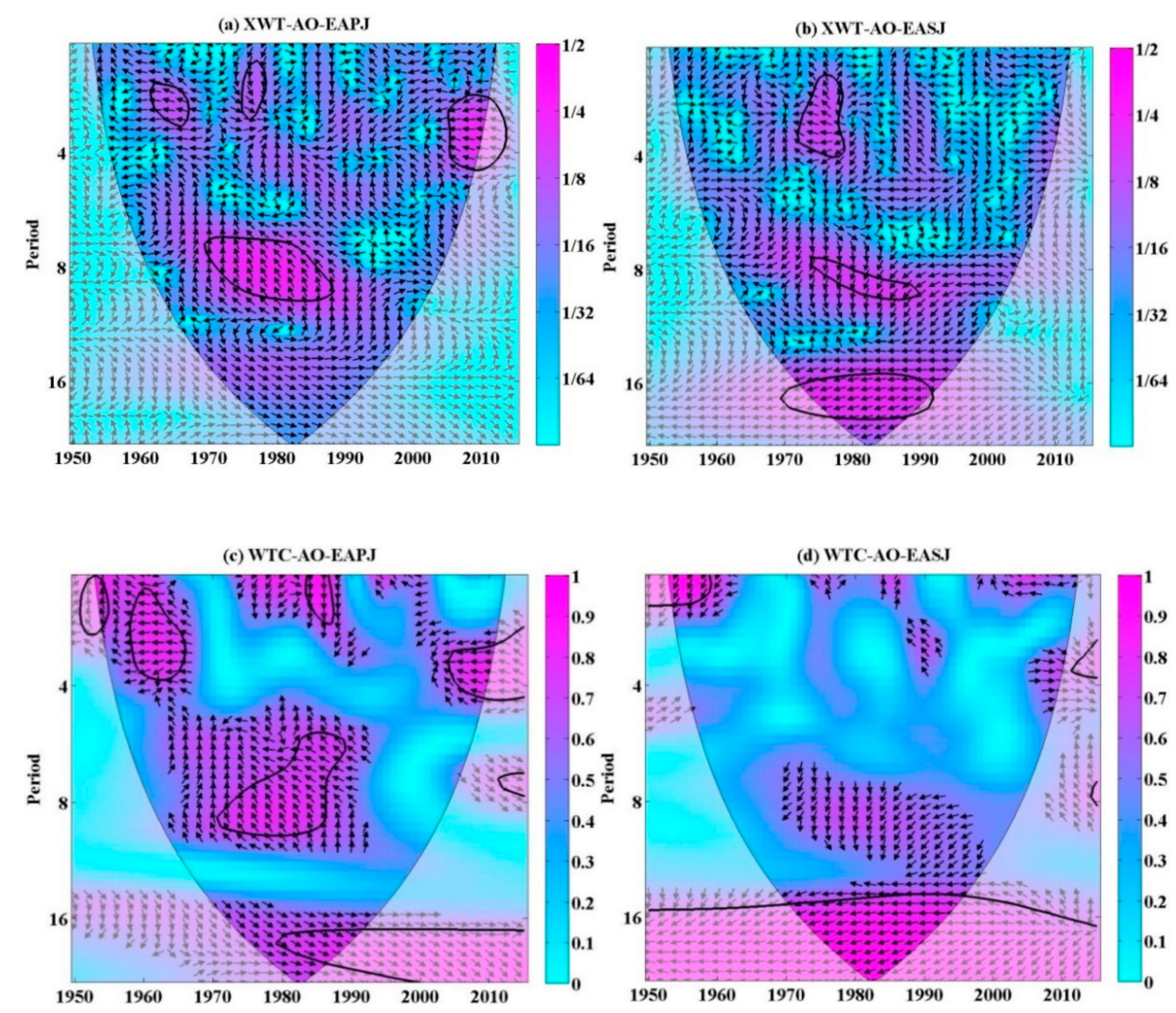

Figure 5. Cross-wavelet transform (XWT) of the (a) Arctic Oscillation and EAPJ and (b) Arctic Oscillation and EASJ, and the squared wavelet coherence (WTC) of the (c) Arctic Oscillation and EAPJ and (d) Arctic Oscillation and EASJ during the winters of 1950-2016. The thick black contour shows the $5 \%$ significance level against red noise, and the thin black line indicates the cone of influence where edge effects might distort the picture shown in a lighter shade. 
The significant common power for the XWT of the Arctic Oscillation and the EASJ is located in roughly the 3 to 5-year band in the 1970s and the 6 to 10- and 15 to 20-year bands during the period 1970-1990 (Figure 5b). It tends primarily to present as antiphase in the 3 to 5 - and 15 to 20-year bands, but the Arctic Oscillation is leading the EASJ in the 6 to 10-year band. It seems the phase connections between the Arctic Oscillation and EAPJ/EASJ are more complex than the phase linkage between the AKT2m and EAPJ/EASJ. The possible causes leading to these results are considered in the discussion section.

\subsection{Wavelet Coherence}

WTC can help to show the intermittent correlations between two phenomena or signals, even at intervals where there is high coherence, but where only minimal power is shown in the wavelet power spectrum of the two processes [41]. Compared with the XWT (Figure 4c), the squared WTC of the AKT2m and EAPJ (Figure 4e) shows a larger significant section. The oscillations in the AKT2m are manifested in the EAPJ at wavelengths varying from 2 to 3.5 years in the 1960s and 3 to 6 years after 2000. The clearest correlation of the AKT2m and EAPJ is in the 2 to 15 -year band localized from the early 1970s to the mid-1980s. All the oscillations show an out-of-phase relationship, which agrees with the negative correlation coefficients found by simple correlations. This suggests that the warmer the AKT2m, the weaker the EAPJ, which is consistent with some previous studies (e.g., [46]).

These analyses show the features of the intermittent correlations between the AKT2 and EAPJ, with a close relationship during the period of abrupt climate change in East Asia [in the early 1980s (Hung and Kao [47]); in the mid-1970s (Dai et al. [14])]. Comparing Figure $4 \mathrm{f}$ with 4e, the squared WTC of the AKT2m and EASJ shows significant in-phase connections only in the 2 to 3.5- and 8 to 10-year bands from the late 1970s to the early 1980s (the period of abrupt climate change in East Asia), which is the same as the positive correlation coefficients between the AKT2m and EASJ. This is similar to some previous conclusions about the intensity of the EAPJ and EASJ in the reverse phase [48-50], but using different methods from a different research perspective. However, there are only a few bands with a clear connection between the AKT2m and EASJ, indicating that the AKT2m and EASJ are largely independent.

The squared WTC of the winter Arctic Oscillation and EAPJ shows a few significant wave bands (Figure 5c) with periods of 2-5 years from the late 1950s to the mid-1960s, 2-3 years in the 1980s, 3-5 years after 2000, 5-10 years from the early 1970s to the late 1980s, and around the 16 to 20 -year interdecadal wave band after the late 1970s. The phase angles tend primarily to present as out-of-phase in the 2 to 5 - and 5 to 10-year bands, but the Arctic Oscillation is leading the EAPJ in the 2 to 3 -year band in the 1980s, and the 16 to 20-year interdecadal wave band presents as in-phase. This implies that the correlation between the Arctic Oscillation and EAPJ is not only intermittent, but is also uncertain and complex. These analyses show that the correlation between the AKT2m and EAPJ is larger than that between the Arctic Oscillation and EAPJ during the study period. Figure $5 \mathrm{~d}$ shows the squared WTC of the winter Arctic Oscillation and EASJ only presents a clear relationship in the longer than 15 -year interdecadal wave and is out-of-phase throughout the study period. All these analyses indicate that the AKT2m and Arctic Oscillation are both more closely related to the EAPJ than to the EASJ, and that the closest correlation is between the AKT2m and EAPJ during the period of abrupt climate change in East Asia.

\section{Summary and Discussion}

The main purpose of this study was to explore the frequency associations and differences between the AKT2m/Arctic Oscillation and the EAPJ/EASJ by analyzing the CWT, XWT and WTC in time-frequency space using NCEP-NCAR reanalysis data. At the same time, the uncertainty in the impact of the Arctic Oscillation on the weather and climate over East Asia relative to that of the AKT2m was analyzed further. Our results can be summarized as follows: 
(1) The CWTs of the AKT2m and Arctic Oscillation show that there is no obvious common significant peak and frequency. The significant common power in the XWT of the AKT2m and the Arctic Oscillation is mainly located at about the 7 to 10-year band from the mid-1970s to the late 1980s. Compared with their XWT, their squared WTC shows a larger section as being significant, which indicates that the correlation of the AKT2 and Arctic Oscillation is, to some extent, in the 5-10-year band from the mid-1960s to the late 1990s. The phase angles of their XWT and squared WTC tend to be in-phase, but the Arctic Oscillation leads the AKT2m - that is, the stronger the positive phase of the Arctic Oscillation, the warmer the Arctic region (AKT2m).

(2) The CWTs of the EAPJ and EASJ not only have a common significant peak in the 3 to 5-year band, but also have different peaks in the 6 to 8 -year band for the EAPJ and the 16 to 20-year band for the EASJ, which implies that they are affected by similar interannual factors, and different interannual and interdecadal factors too.

(3) The XWTs of the AKT2m/Arctic Oscillation and the EAPJ intermittently show the highest common power in the antiphase in the 3 to 5-year band from the 1960s to the 2010s, except the XWT of the Arctic Oscillation and EAPJ in the 1970s. The XWTs of the AKT2m/Arctic Oscillation and the EASJ also show a high common power in the 3 to 5 -year band, but this is limited to the mid-1970s to the early 1980s with in-phase/antiphase correlations.

However, the XWTs of the Arctic Oscillation and EAPJ/EASJ have high common periods not only interannual, but also in the interdecadal periods of the 6 to 10 - and 15 to 20-year period bands. In other words, the XWTs of the Arctic Oscillation and EAPJ/EASJ (Figure 5a,b) show more common period bands than the XWTs of the AKT2m and EAPJ/EASJ (Figure 4c,d), whereas the XWTs of the AKT2m/Arctic Oscillation and EAPJ (Figures 4c and 5a) show a high common period at more times than the XWTs of the AKT2m/Arctic Oscillation and EASJ (Figures 4d and 5b).

(4) The squared WTC of the AKT2m and EAPJ presents the clearest antiphase correlation in the 2 to 15 -year band from the early 1970s to the mid-1980s, indicating that the weakening of the EAPJ is associated with the rise in AKT2m, especially during the period of abrupt climate change over East Asia. By contrast, the correlation of the AKT2m and EAPJ is closer than that of the Arctic Oscillation and EAPJ. The latter relationship is uncertain and complex due to the variability of the phase angle.

The squared WTC of the AKT2m and EASJ shows little connection, indicating that the AKT2m and EASJ are largely independent of each other. The squared WTC of the Arctic Oscillation and EASJ only shows a clear relationship at time periods longer than the 15-year interdecadal wave band, which presents as antiphase during the whole research period. This analysis indicates that both the AKT2m and Arctic Oscillation are more closely related to the EAPJ than to the EASJ.

The phase angle distribution is more complex in the XWTs and WTCs of the Arctic Oscillation and EAPJ/EASJ than in the AKT2m and EAPJ/EASJ. For there to be a simple cause-and-effect relationship between the phenomena recorded in the time series, we would expect the oscillations to be phase-locked [34]. Consistent or slowly changing phase angles can be considered as evidence of significant phase relationships [41]. Therefore, the associations between the Arctic Oscillation and EAPJ/EASJ are both uncertain and complex, possibly due to the overlapping influence of multiple variations and the non-linear impact of some factors. The Arctic Oscillation itself contains direct information not only from the Arctic, but also from mid-latitudes in the Northern Hemisphere. It has been shown that the Arctic Oscillation, the most representative atmospheric variation of the internal dynamics of the Northern Hemisphere circulation during cold seasons, is closely connected to the behavior of the EAWM [18,51,52]. However, the Arctic Oscillation is unclearly and intricately linked to the EAPJ, while the EAPJ is closely related with the EAWM [32,53]. The problem becomes more complex and difficult to explain by simple linear analysis because the included information from different latitudes will be affected by the same and different influencing factors. It is by no means guaranteed that the anomalous weather and climate that the Arctic Oscillation tends to generate will dominate in East Asia. We should be cautious in our predictions of climate based on the Arctic Oscillation [54]. The impact of the Arctic Oscillation on changes in the winter climate of East Asia 
is spatially and temporarily dependent. The impact of the winter Arctic Oscillation on the Eurasian surface air temperature and cold surges might show decadal changes [55].

Comparison of the WTC and the XWT between the AKT2m/Arctic Oscillation and EAPJ shows that their significant correlation covers their common power and even no common power in time-frequency space, such as the 5 to 15-year band in the WTC of the AKT2m and EAPJ (comparing Figure 4c,e) and the 16 to 20-year interdecadal wave band in the WTC of the Arctic Oscillation and EAPJ (comparing Figure 5a,c). However, a comparison of the WTC and XWT between the Arctic Oscillation and EASJ (comparing Figure $5 b, d$ ) shows that similar situations are not always true and become more complex. The XWT of the Arctic Oscillation and EASJ shows a significant common power located in roughly the 3 to 5-year band in the 1970s and the 6 to 10- and 15 to 20-year bands during the period 1970-1990 (Figure $5 b$ ), whereas the WTC only presents a clear relationship at times longer than the 15-year interdecadal band. This suggests that the Arctic Oscillation is not closely related to the EASJ on an interannual timescale and represents complex information.

The Arctic Oscillation is a key aspect of climate variability in the Northern Hemisphere. The Arctic Oscillation is defined as the leading EOF of the Northern Hemisphere SLP anomalies poleward of $20^{\circ} \mathrm{N}[38,56]$ and is characterized by an exchange of atmospheric mass between the Arctic and mid-latitudes [34] - that is, the Arctic Oscillation represents a matching relationship between the Arctic and mid-latitudes that contains information about the changes in the Arctic and the mid-latitudes together. In other words, it is better to study the impact of Arctic warming on the weather and climate over East Asia directly using the conditions of the Arctic itself (e.g., AKTm2), than using the Arctic Oscillation to represent it.

Author Contributions: Conceptualization, Y.L.; Data curation, Y.L. and Y.Z.; Formal analysis, Y.L.; Funding acquisition, Y.L.; Investigation, Y.L.; Methodology, Y.L.; Project administration, Y.L.; Resources, Y.L.; Software, Y.Z. and W.S.; Supervision, Y.L.; Validation, Y.L.; Visualization, Y.L. All authors have read and agreed to the published version of the manuscript.

Funding: This research was funded by the National Natural Science Foundation of China (grant numbers 41675095 and 41675107).

Acknowledgments: The authors would like to thank the National Centers for Environmental Prediction (NCEP) and the National Center for Atmospheric Research (NCAR) of the United States of America for the valuable reanalysis data, and the National Oceanic and Atmospheric Administration (NOAA) Climate Prediction Center (CPC) for the $\mathrm{AO}$ index.

Conflicts of Interest: The authors declare no conflict of interest.

\section{References}

1. Serreze, M.C.; Barry, R.G. Synoptic activity in the Arctic Basin, 1979-1985. J. Clim. 1988, 1, $1276-1295$. [CrossRef]

2. Serreze, M.C.; Walsh, J.E.; Chapin, F.S.; Osterkamp, T.; Dyurgerov, M.; Romonovsky, V.; Oechel, W.C.; Morison, J.; Zhang, T.; Barry, R.G. Observational evidence of recent change in the northern high-latitude environment. Clim. Chang. 2000, 46, 159-207. [CrossRef]

3. Semenov, V.A.; Latif, M.; Dommenget, D.; Keenlyside, N.S.; Strehz, A.; Martin, T.; Park, W. The impact of North Atlantic-Arctic multidecadal variability on Northern Hemisphere surface air temperature. J. Clim. 2010, 23, 5668-5677. [CrossRef]

4. Hegerl, G.C.; Zwiers, F.W.; Braconnot, P.; Gillett, N.P.; Luo, Y.; Marengo Orsini, J.A.; Nicholls, N.; Penner, J.E.; Stott, P.A. Understanding and attributing climate change. In Climate Change 2007: The Physical Science Basis. Contribution of Working Group I to the Fourth Assessment Report of the Intergovernmental Panel on Climate Change; Solomon, S., Qin, D., Manning, M., Chen, Z., Marquis, M., Averyt, K.B., Tignor, M., Miller, H.L., Eds.; Cambridge University Press: Cambridge, UK, 2007; pp. 663-745.

5. Min, S.K.; Zhang, X.B.; Zwiers, F. Human-induced arctic moistening. Science 2008, 320, 518-520. [CrossRef] [PubMed]

6. Overland, J.E. A difficult Arctic science issue: Midlatitude weather linkages. Polar Sci. 2016, 10, $210-216$. [CrossRef] 
7. Deser, C.; Teng, H. Evolution of Arctic sea ice concentration trends and the role of atmospheric circulation forcing, 1979-2007. Geophys. Res. Lett. 2008, 35, L02504. [CrossRef]

8. Peings, Y.; Magnusdottir, G. Response of the wintertime Northern Hemisphere atmospheric circulation to current and projected Arctic sea ice decline: A numerical study with CAM5. J. Clim. 2014, 27, 244-264. [CrossRef]

9. Honda, M.; Yamazaki, K.; Nakamura, H.; Takeuchi, K. Dynamic and Thermodynamic characteristics of atmospheric response to anomalous sea ice extent in the Sea of Okhotsk. J. Clim. 1999, 12, 3347-3358. [CrossRef]

10. Parkinson, C.L. The impacts of the Siberian high and Aleutian low on the sea-ice cover of the Sea of Okhotsk. Ann. Glaciol. 1990, 14, 226-229. [CrossRef]

11. Liu, J.; Zhang, Z.; Horton, R.M.; Wang, C.; Ren, X. Variability of North Pacific sea ice and East Asia-North Pacific winter climate. J. Clim. 2007, 20, 1991-2001. [CrossRef]

12. Linkin, M.E.; Nigam, S. The North Pacific oscillation-west Pacific teleconnection pattern: Mature-phase structure and winter impacts. J. Clim. 2008, 21, 1979-1997. [CrossRef]

13. Matthewman, N.J.; Magnusdottir, G. Observed interaction between Pacific sea ice and the western Pacific pattern on intraseasonal time scales. J. Clim. 2011, 24, 5031-5042. [CrossRef]

14. Dai, T.L.; Dong, W.J.; Guo, Y.; Hong, T.; Ji, D.; Yang, S.L.; Tian, D.; Wen, X.H.; Zhu, X. Understanding the abrupt climate change in the mid-1970s from a phase-space transform perspective. J. Appl. Meteorol. Clim. 2018, 57, 2551-2560. [CrossRef]

15. Maslanik, J.; Drobot, S.; Fowler, C.; Emery, W.; Barry, R. On the Arctic climate paradox and the continuing role of atmospheric circulation in affecting sea ice conditions. Geophys. Res. Lett. 2007, 34, L03711. [CrossRef]

16. Budikova, D. Role of Arctic sea ice in global atmospheric circulation: A review. Glob. Planet. Chang. 2009, 68, 149-163. [CrossRef]

17. Gong, D.Y.; Wang, S.W.; Zhu, J.H. East Asian winter monsoon and Arctic oscillation. Geophys. Res. Lett. 2001, 28, 2073-2076. [CrossRef]

18. Park, T.W.; Ho, C.H.; Yang, S. Relationship between the Arctic oscillation and cold surges over East Asia. J. Clim. 2011, 24, 68-83. [CrossRef]

19. Walsh, J.E.; Chapman, W.L. Short-term climatic variability of the Arctic. J. Clim. 1990, 3, 237-250. [CrossRef]

20. Dethloff, K.; Rinke, A.; Benkel, A.; Køltzow, M.; Sokolova, E.; Kumar, S.S.; Handorf, D.; Dorn, W.; Rockel, B.; Storch, H. A dynamical link between the Arctic and the global climate system. Geophys. Res. Lett. 2006, 33, L03703. [CrossRef]

21. Wu, B.Y.; Zhang, R.H.; D'arrigo, R. Distinct modes of the East Asian winter monsoon. Mon. Weather Rev. 2006, 134, 2165-2179. [CrossRef]

22. Wu, B.Y.; Wang, J. Winter arctic oscillation, siberian high and east asian winter monsoon. Geophys. Res. Lett. 2002, 29, 31-34. [CrossRef]

23. Li, Y.F.; Leung, L.R. Potential impacts of the Arctic on interannual and interdecadal summer precipitation over China. J. Clim. 2013, 26, 899-917. [CrossRef]

24. Li, F.; Wang, H.J.; Gao, Y.G. On the strengthened relationship between the East Asian winter monsoon and Arctic Oscillation: A comparison of 1950-1970 and 1983-2012. J. Clim. 2014, 27, 5075-5091. [CrossRef]

25. Woo, S.H.; Kim, B.M.; Kug, J.S. Temperature variation over East Asia during the lifecycle of weak stratospheric polar vortex. J. Clim. 2015, 28, 5857-5872. [CrossRef]

26. Tao, S.Y.; Chen, L.X. A review of recent research of the East Asian summer monsoon in China. In Monsoon Meteorology; Oxford University Press: Oxford, UK, 1985; pp. 60-92.

27. Yang, S.; Lau, K.M.; Kim, K.M. Variations of the East Asian jet stream and Asian-Pacific-American winter climate anomalies. J. Clim. 2002, 15, 306-325. [CrossRef]

28. Yim, B.Y.; Min, H.S.; Kug, J.S. Inter-model diversity in jet stream changes and its relation to Arctic climate in CMIP5. Clim. Dyn. 2016, 47, 235-248. [CrossRef]

29. Zhang, Y.; Huang, D. Has the East Asian westerly jet experienced a poleward displacement in recent decades? Adv. Atmos. Sci. 2011, 28, 1259-1265. [CrossRef]

30. Huang, D.Q.; Dai, A.G.; Zhu, J.; Zhang, Y.C.; Kuang, X.Y. Recent winter precipitation changes over eastern china in different warming periods and the associated east asian jets and oceanic conditions. J. Clim. 2017, 30, 4443-4462. [CrossRef] 
31. Overland, J.E.; Wang, M.Y. Arctic-midlatitude weather linkages in North America. Polar Sci. 2018, 16, 1-9. [CrossRef]

32. Song, W.; Wu, Z.W.; Li, Y.F.; Liu, C. Interannual association of the near-surface temperature between Eastern China and the Arctic in winter. Clim. Environ. Res. 2018, 23, 463-478. (In Chinese)

33. Li, Y.F.; Leung, L.R.; Xiao, Z.N.; Wei, M.; Li, Q.Q. Interdecadal connection between Arctic temperature and summer precipitation over the Yangtze River Valley in the CMIP5 historical simulations. J. Clim. 2013, 26, 7464-7488. [CrossRef]

34. Grinsted, A.; Moore, J.C.; Jevrejeva, S. Application of the cross wavelet transform and wavelet coherence to geophysical time series. Nonlinear Proc. Geophys. 2004, 11, 561-566. [CrossRef]

35. Kalnay, E.; Kanamitsu, M.; Kistler, R.; Collins, W.; Deaven, D.; Gandin, L.; Iredell, M.; Saha, S.; White, G.; Woollen, J.; et al. The NCEP/NCAR 40-year reanalysis project. Bull. Am. Meteorol. Soc. 1996, 77, 437-470. [CrossRef]

36. Wu, B.Y.; Huang, R.H.; Gao, D.Y. The impact of variation of sea-ice extent in the Kara Sea and the Barents Seas in winter on the winter monsoon over East Asia. Chin. J. Atmos. Sci. 1999, 23, 267-275.

37. Kug, J.S.; Jeong, J.H.; Jang, Y.S.; Kim, B.M.; Folland, C.K.; Min, S.K.; Son, S.W. Two distinct influences of Arctic warming on cold winters over North America and East Asia. Nat. Geosci. 2015, 8, 759-762. [CrossRef]

38. Thompson, D.W.J.; Wallace, J.M. The Arctic oscillation signature in the wintertime geopotential height and temperature fields. Geophys. Res. Lett. 1998, 25, 1297-1300. [CrossRef]

39. Baldwin, M.P.; Dunkerton, T.J. Propagation of the Arctic oscillation from the stratosphere to the troposphere. J. Geophys. Res. 1999, 104, 30937-30946. [CrossRef]

40. Torrence, C.; Compo, G.P. A Practical Guide to Wavelet Analysis. Bull. Am. Meteorol. Soc. 1998, 79, 61-78. [CrossRef]

41. Ng, E.K.W.; Chan, J.C.L. Geophysical applications of partial wavelet coherence and multiple wavelet coherence. J. Atmos. Ocean. Technol. 2012, 29, 1845-1853. [CrossRef]

42. Gurley, K.; Kareem, A. Applications of wavelet transforms in earthquake, wind and ocean engineering. Eng. Struct. 1999, 21, 149-167.

43. Gurley, K.; Kijewski, T.; Kareem, A. First- and higher-order correlation detection using wavelet transforms. J. Eng. Mech. 2003, 129, 188-201. [CrossRef]

44. Yates, T.T.; Si, B.C.; Farrell, R.E.; Pennock, D.J. Time, location, and scale dependence of soil nitrous oxide emissions, soil water, and temperature using wavelets, cross-wavelets, and wavelet coherency analysis. J. Geophys. Res. 2007, 112, D9-D104. [CrossRef]

45. Ye, D.; Zhang, Y.C. Association of concurrent variation between the East Asian polar front and subtropical jets with winter cold air activity in China. Chin. J. Atmos. Sci. 2014, 38, 146-158.

46. Overland, J.E.; Francis, J.A.; Hall, R.; Hanna, E.; Kim, S.J.; Vihma, T. The melting Arctic and midlatitude weather patterns: Are they connected? J. Clim. 2015, 28, 7917-7932. [CrossRef]

47. Hung, C.W.; Kao, P.K. Weakening of the winter monsoon and abrupt increase of winter rainfalls over northern Taiwan and southern China in the early 1980s. J Clim. 2010, 23, 2357-2367. [CrossRef]

48. Zhang, Y.C.; Xiao, C.L. Variability modes of the winter upper-level wind field over Asian mid-high latitude region. Atmos. Ocean. Sci. Lett. 2013, 6, 295-299.

49. Luo, X.; Zhang, Y.C. The linkage between upper-level jet streams over East Asia and East Asian winter monsoon variability. J. Clim. 2015, 28, 9013-9028. [CrossRef]

50. Xiao, C.L.; Zhang, Y.C.; Lofgren, B.M.; Nie, Y. The concurrent variability of East Asian subtropical and polar-front jets and its implication for the winter climate anomaly in China. J. Geophys. Res. Atmos. 2016, 121, 6787-6801. [CrossRef]

51. Cheung, H.N.; Zhou, W.; Mok, H.Y.; Wu, M.C. Relationship between Ural-Siberian blocking and the East Asian winter monsoon in relation to the Arctic oscillation and the El Niño-Southern oscillation. J. Clim. 2012, 25, 4242-4257. [CrossRef]

52. Ding, Y.H.; Liu, Y.J.; Liang, S.J.; Ma, X.Q.; Zhang, Y.X.; Si, D.; Liang, P.; Song, Y.F.; Zhang, J. Interdecadal variability of the East Asian winter monsoon and its possible links to global climate change. J. Meteorol. Res. 2014, 28, 693-713. [CrossRef]

53. Song, W.; Li, Y.F.; Wu, Z.W. Comparative analysis of cold events over central and eastern China associated with Arctic warming in early 2008 and 2016. Atmos. Ocean 2020, 1-17. [CrossRef] 
54. He, S.P.; Gao, Y.Q.; Li, F.; Wang, H.J.; He, Y.C. Impact of Arctic oscillation on the East Asian climate: A review. Earth Sci. Rev. 2017, 164, 48-62. [CrossRef]

55. Woo, S.H.; Kim, B.M.; Jeong, J.H.; Kim, S.J.; Lim, G.H. Decadal changes in surface air temperature variability and cold surge characteristics over northeast Asia and their relation with the Arctic Oscillation for the past three decades (1979-2011). J. Geophys. Res. Atmos. 2012, 117, D18117. [CrossRef]

56. Ambaum, M.H.P.; Hoskins, B.J.; Stephenson, D.B. Arctic Oscillation or North Atlantic Oscillation? J. Clim. 2001, 14, 3495-3507. [CrossRef]

(C) 2020 by the authors. Licensee MDPI, Basel, Switzerland. This article is an open access article distributed under the terms and conditions of the Creative Commons Attribution (CC BY) license (http://creativecommons.org/licenses/by/4.0/). 